\title{
Filariasis Morbidity, Environment and Socio-Economic Situation: A Hot Spot Analysis on Northern Region of Bangladesh
}

\author{
Dr. Md. Rashed Karim ${ }^{1 *}$, Sheikh Md. Monzurul Huq ${ }^{2}$, Shams Shaila Islam ${ }^{3}$ \\ ${ }^{1}$ Assistant Professor, Department of Geography and Environment, Government Saroda Shundori Mohila \\ College, Faridpur, Bangladesh \\ ${ }^{2}$ Professor, Department of Geography and Environment, Jahangirnagsr University, Savar, Dhaka, Bangladesh \\ ${ }^{3}$ Assistant Professor, Department of Agronomy, Hajee Mohammad Danesh Science and Technology University, \\ Dinajpur, Bangladesh
}

${ }^{*}$ Corresponding Author: Dr. Md. Rashed Karim, Assistant Professor, Department of Geography and Environment, Government Saroda Shundori Mohila College, Faridpur, Bangladesh

\begin{abstract}
Now a day disease is of interest to the geographers for several reasons. Geography of disease is fully understood by explaining a variety of factors, such as, climate, culture, geology, socio-economic status, biology etc. There are number of events which are concentrated in some specific places. For example, traffic accidents, disease outbreaks, gentrification, crime etc. When a geographer analyses a particular disease, including prediction, a key element centers where is the disease outbreak concentrated. Disease occurrences are not distributed randomly through spaces. Their distribution is dense at some locations while sparse at others. The places where disease incidents are relatively densely distributed are called hotspots. In this study, the filariasis morbidity pattern for the study area is investigated and analyzed. Analyses of data are performed using the Spatial Statistics Hot Spot Analysis tool, a spatial statistical technique which uses the Getis-Ord Gi* algorithm. This type of analysis helps to identify statistically significant spatial clusters of high and low filariasis morbidity in the study area.
\end{abstract}

Keywords: Hot Spot Analysis, Filariasis, ArcGis, Getis-ord, z-score

\section{BACKGRound OF THE STUdY}

Filariasis is mosquito borne infectious disease of human. Filariasis is a group of human and animal infectious disease caused by nematode parasites of the order filrioidea, commonly called filariae (Sasa, 1976:55). It is a communicable parasitic disease caused by Wuchereria bancrofti, Brugia malayi or Brugia timori that can clinically manifest itself in the form of lymphedema or elephantiasis (WHO, 2001). Filariasis has been identified as a major public health problem and is endemic in over 80 countries (Ngwira et al., 2007). It is the world's second leading cause of long-term disability (WHO, 1995). Currently, more than 1.4 billion people in 73 countries are living in areas where filariasis is transmitted and are at risk of being infected (WHO, 2010). Approximately 80 percent of these people are living in the following 10 countries: Bangladesh, Democratic Republic of Congo, Ethiopia, India, Indonesia, Myanmar, Nigeria, Nepal, Philippines and the United Republic of Tanzania. It is currently estimated that up to 120 million people are infected with Wuchereria bancrofti in about 83 endemic countries (Michale et al., 1996). Of these, about 40 million people have evidence of chronic manifestation such as, elephantiasis (Ngwira et al. 2007). Globally, an estimated 25 million men suffer with genital disease due to filariasis and over 15 million people are afflicted with lymphoedema (Kanda, 2004).

Filariasis receives much less international attention than other infectious diseases such as Malaria, Tuberculosis (TB) and Acquired Immune Deficiency Syndrome (AIDS) because people do not die as a direct consequence of filariasis. Filariasis is almost entirely a disease of poor community. According to Sasa (1976) Filariasis is ignored and neglected by the developed world, as the disease is not fatal. Filariasis is seen in developing countries of the world, as a result filariasis control program received little financial support the disease exists within the context of poverty and, it makes someone very weak and infirm. Continuously growing physically weaken condition contributes significantly to the ongoing incapacity of affected individuals and their families to escape poverty (Durrheim, et al., 
2004). Filariasis Infection is usually acquired in childhood causing hidden damage to the lymphatic system. The painful and profoundly disfiguring visible manifestations of the disease, lymphoedema, elephantiasis and scrotal swelling occur later in life and lead to permanent disability. Acute filarial attacks account for significant loss of productive days of risk population. More severely affected people have social stigma and they are also physically burdened. These patients are not only physically disabled, but suffer mental, social and financial losses contributing to social stigma and poverty.

Bangladesh is a country of divergent climatic condition throughout the year which has a complex influence in economic and social aspects, mainly for its geographic location and physiographic situation. Most of the people of the country live in the rural areas and a large umber of them are poor. Filariasis is the disease of the poor people and totally neglected for more than 50 years in Bangladesh and it is endemic in 34 out of 64 districts so far (IACIB, 2011). The affected people are generally the poorest and most vulnerable segment of the country. When geographers conduct disease analysis using the techniques such as, spatial distribution, spatial association and prediction, a key aspect centers on where disease have a tendency to occur. Disease incidents, in general, are not distributed randomly throughout space. Their distribution is dense at some locations while sparse at others (Fan, 2012). Disease is of interest to geographers for a variety of reasons and to fully understand the geography of disease, one should judge many factors. For example, the housing, literacy, toilet facilities, humidity, agriculture practices, socio-cultural milieu and overall environment of a particular region influence the incidence of filariasis. A study has revealed that there was high endemicity of filariasis in Nilphamari, Thakurgaon, Dinajpur, Rangpur, Panchagarh, Kurigram, and Lalmonirhat of Bangladesh (Health Bulletin Report, 2014). Directorate General Health Services of Bangladesh estimated that about 70 million were at risk of infection while 1 million people were with various forms of clinical deformity, and another 10 million people are affected with microfilariae (DGHS, 2014). Although there has been a significant advancement in GIS and its application in disease analysis, its use is rather low in underdeveloped countries like Bangladesh. Very few studies have applied GIS tool to study disease causation and situation of the population of the country. In this study the Filariasis morbidity pattern for the study area is investigated and analyzed. Analyses of data are performed using the Spatial Statistics Hot Spot Analysis tool, a spatial statistical technique which uses the Getis-Ord Gi* algorithm. This type of analysis helps to identify statistically significant spatial clusters of high and low Filariasis morbidity in the study area. The present study focuses on the Filariasis situation of the population of Northern region (Rangpur Division), relatively backward regions of the country. This study specifically focuses on morbidity situation due to Filariasis, physical environment and socio-economic aspects of the study area.

\section{Rationale Of The Study}

In Bangladesh, the disease is present all over the country with highest endemicity in northern parts of the country. The northern region of Bangladesh is lagging behind from various social and economic developments. A broad range of physical and socio-economic factors such as, rainfall, temperature, humidity, vegetation cover, poverty, over-crowded accommodation, poor level of hygiene practice, inadequate nutrition, ignorance of people, lack of awareness, provide ideal conditions for Filariasis to spread. Out of 147 million people in the area has been suffering from the disease. The exact figures of Filariasis in Bangladesh are not known, but it is at present now in 33 endemic districts out of 64 districts as revealed by study done by WHO completed in 2002 and 2004 (DGHS, 2012). There is high endemicity of Filariasis in Nilfamari, Thakurgaon, Dinajpur, Lalmonirhat, Rangpur, Panchagarh, Kurigram, Gaibandha, Chapai Nawabganj and Rajshahi districts. It is estimated that 70 million are at risk of infection, while 10 million have various forms of deformity (DGHS, 2012). The fact is that Filariasis is ignored and neglected by the developing world like Bangladesh, as the disease is not fatal. As because a marginalized population is affected by this disease, there is little incentive for pharmaceutical companies to develop improved drugs or vaccines for their prevention and treatment of the disease. Moreover, there is lack of trained personnel to manage and analyze these data from spatial perspective. As a result, several development programs on filarial elimination initiated by both the government and non-government organizations have failed in the recent past. The impact of the total environment (physical, human and biological) on the transmission of filariasis has received insufficient attention from researchers and different organizations of the country. Many studies have 
focused on malaria but a very few studies have been carried out regarding the neglected tropical diseases like Filariasis (DGHS, 2012). In this study an attempt has been made to examine and analyze the morbidity occurrences concentration due to Filariasis in the study area.

The concept of a hotspot is widely used in our daily life. Being aware of which places are safer and which places are with a higher risk of being a victim of disease incidence, people visit or live in some locations while they avoid others. Based on the knowledge of risks of victimization of any diseases, people for example make choices of the communities they live in (Fan, 2012). The hotspot concept is also of critical importance to the policy maker to take necessary actions. Provided with information about the specific spread of disease and the information of hotspots of the disease, authority could then make more appropriate decisions about where and when to allocate limited manpower, resources etc. to the places where services demands are at the highest (Shelton, 2014). Hot spot analysis and hotspot mapping is paid most attention among disease mapping among the medical geographers.

ArcGis (ArcMap), version 10.2.1 helped to do the task. The Hot Spot Analysis tool of mapping clusters toolset of ArcGis calculates the Getis-Ord Gi* statistic (pronounced G-i-star) for each feature in a dataset. The resultant $\mathrm{z}$-scores and p-values tell where features with either high or low values cluster spatially. This tool works by looking at each feature within the context of neighboring features. A feature with a high value is interesting but may not be a statistically significant hot spot. To be a statistically significant hot spot, a feature will have a high value and be surrounded by other features with high values as well. The local sum for a feature and its neighbors is compared proportionally to the sum of all features; when the local sum is very different from the expected local sum, and when that difference is too large to be the result of random chance, a statistically significant $z$-score results (ESRI, 2014).

The Hot Spot Analysis (Getis- Ord Gi*) tool identifies statistically significant hot spots (high values) and cold spots (low values) using the Getis - Ord Gi* statistic. It creates a z - score, p- value, and confidence level bin (Gi_Bin) value for each input feature. The $\mathrm{z}$ - scores and $\mathrm{p}$ - values indicate whether the observed spatial clustering of high or low values is more pronounced than one would expect in a random distribution of those same values. A feature that has no apparent spatial clustering is indicated by a $\mathrm{z}$ - score nearer to zero. The higher (or lower) the $\mathrm{z}-$ score is, the more intense is the clustering. A high $\mathrm{z}$ - score and small $\mathrm{p}$ - value for a feature indicates a spatial clustering of high values. A low negative e $\mathrm{z}$ - score and small $\mathrm{p}$ - value indicates a spatial clustering of low values.

\subsection{Calculations of Hot Spots}

The Getis-ord local static is given as:

$$
\begin{aligned}
G_{i}^{*}= & \frac{\sum_{j=1}^{n} w i . j x j-\bar{X} \sum_{j=1}^{n} w i, j}{\left[n \sqrt{\left[n \sum_{j=1}^{n} w^{2} i, j-\left(\sum_{j=1}^{n} w i, j\right)^{2}\right]}\right.}
\end{aligned}
$$

Where $x_{j}$ is the attribute value for $j, w_{i, j}$ is the spatial weight between feature $I$ and $j, n$ is equal to the total number of features and :

$$
\begin{gathered}
\bar{X}=\frac{\sum_{j=1}^{n} x_{i}}{n} \\
S=\sqrt{\frac{\sum_{j=1}^{n} x^{2} i}{n}-(\bar{x})^{2}}
\end{gathered}
$$

The $\mathrm{G}_{\mathrm{i}}^{*}$ static is a $\mathrm{z}$ score so no further calculations are required 
The Gi_Bin field assigns features identified as statistically significant hot and cold spots. Features that reflect a statistical significance at a 99 percent confidence level are assigned $+/-3$ bins; features that reflect a 95 percent confidence level are in the $+/-2$ bins; features in the $+/-1$ bins reflect a 90 percent level; and bin 0 is for features that do not reflect statistically significant clustering. A hot spot is a feature that is identified as having a statistically significant positive $\mathrm{z}-$ score. The larger the $\mathrm{z}-$ score is, the more intense is the clustering of high values. A cold spot is a feature that is identified as having a statistically significant negative $\mathrm{z}$ - score. The smaller the $\mathrm{z}-$ score is, the more intense is the clustering of low values.

\section{STUdy AREA}

The area of this study is northern region (Rangpur Division) of Bangladesh. The region is administratively under Rangpur division, the northernmost division of Bangladesh. The district is bounded on the north by the province of West Bengal Assam state of India, Joypurhat and Bogra districts on the south, Jamalpur district on the east and West Bengal state of India on the west. The study area comprises an area of $16320.26 \mathrm{sq} \mathrm{km}$. The area is located in between in between $25^{\circ} 20^{\prime}$ and $26^{\circ} 37^{\prime}$ north latitudes and in between $88^{\circ} 50^{\prime}$ and $89^{\circ} 53^{\prime}$ east longitudes. The study area is comprised of flat alluvial plain, which gently slopes southward with a number of big rivers. The drainage pattern is braided, with broad, smooth, but irregular-shaped ridges crossed by numerous, broad shallow channels which frequently branch out and reconnect. There is a considerable variation in the type and nature of soil belonging to different parts of the study area. Old Himalayan Piedmont Plain has deep rapidly permeable sandy loams and sandy clay loams are predominant in the region. The region is exposed to cold waves during winter due to its proximity to the Himalayas. Summer, the hottest season of the year, starts from early March and continuous till the middle of June. The average maximum and minimum temperature in summer is about $39^{\circ} \mathrm{c}$ and $7^{\circ}-10^{\circ} \mathrm{c}$ during the winter. The study area i.e. Rangpur division has a total number of 15,665,000 population of which 7824000 male and 7840000 female and the population growth rate is 1.2 (BBS, 2011).

\section{Data ANd ReSEarch Methods}

This study used quantitative methods. Quantitative data are anything that can be expressed as a number, or quantified. Examples of quantitative data are population density, number of male and female, or weight of a subject. In the first phase, the quantitative data on Filariasis morbidity, socioeconomic and environmental issues (based on literature review) were collected. For collection of quantitative data various secondary sources were used. A number of organizations such as, Filariasis Hospital and Center for Disease Control, Sayedpur, Nilphamari, Bangladesh Bureau of Statistics (BBS), Bangladesh Meteorological Department (BMD) and Bangladesh Agricultural Council (BARC) provided necessary information. Demographic data were collected from the population census 2011 report (B. B. S., 2011). Data on total population, number of male and female, population density, literacy rate were collected from the population and housing census published by Bangladesh Bureau of Statistics (BBS, 2011). The economic data consisted of household material, having toilet facilities were also collected from the population and housing census of 2011 (BBS, 2011).

Data on environmental parameters such as annual mean maximum and minimum temperature, annual mean rainfall, annual mean relative humidity and data on irrigated areas on the upazilas of the study area has been collected from Bangladesh Bureau of Statistics (BBS), Bangladesh Meteorological Department (BMD). Bangladesh Agricultural Research Council (BARC) also provided necessary data in this respect. Data on Filariasis morbidity was collected from the Filariasis hospital and center for disease control located in Sayedpur of Nilphamari district. This hospital keeps the patients attendance report in several register book containing name, age, sex, address, disease diagnostics etc. The Local Government And Engineering Department (LGED) of Bangladesh provided Spatial Data. LGED is one of the leading organizations, which has developed a comprehensive spatial database for all Upazilas of Bangladesh. The digital data of 58 upazilas of Rangpur Division (1: 50000 scale), were collected from LGED which depict many human and physical features.

\section{RESULT AND DISCUSSION}

Based on the dataset, Filariasis incidents of 2012 were used which are collected from the Filariasis Hospital, situated in Sayedpur. The kernel density is chosen to be used as the technique to produce spatial hotspot maps (ESRI, 2014). The result of the Hot Spot Analysis tool is a new feature class 
where every feature in the dataset is symbolized based on whether it is part of a statistically significant hot spot, a statistically significant cold spot, or is not part of any statistically significant cluster. The red areas are hot spots or areas where high numbers of Filariasis morbidity surrounded by other areas with high numbers of Filariasis morbidities. The blue areas are cold spots or areas where low numbers Filariasis incidents are surrounded by other areas with low numbers of Filariasis morbidities. The beige areas are not part of statistically significant clusters (Fan, 2012). Statistical significance is based on p-values and z-scores that are calculated when Hot Spot Analysis is carried out.

The results of the Hot Spot Analysis are shown in (Map 1). The map depicts that Nilphamary Sadar, Jaldhaka, Kishorganj, Sayedpur, Khansama, and Taraganj upazilas had very high number of filariasis incidents (hot spot) which reflect a statistical significance at a 99 percent confidence level. Domar and Badarganj upazila with features (hot spot) that reflect a statistical significance at a 95 percent confidence level. Parbatipur upazila shows (hot spot) 90 percent significance level. On the other hand, only Sundarganj upazila had the disease occurrence of cold spot with statistical significance at a 90 percent confidence level. Other areas are not statistically significant.

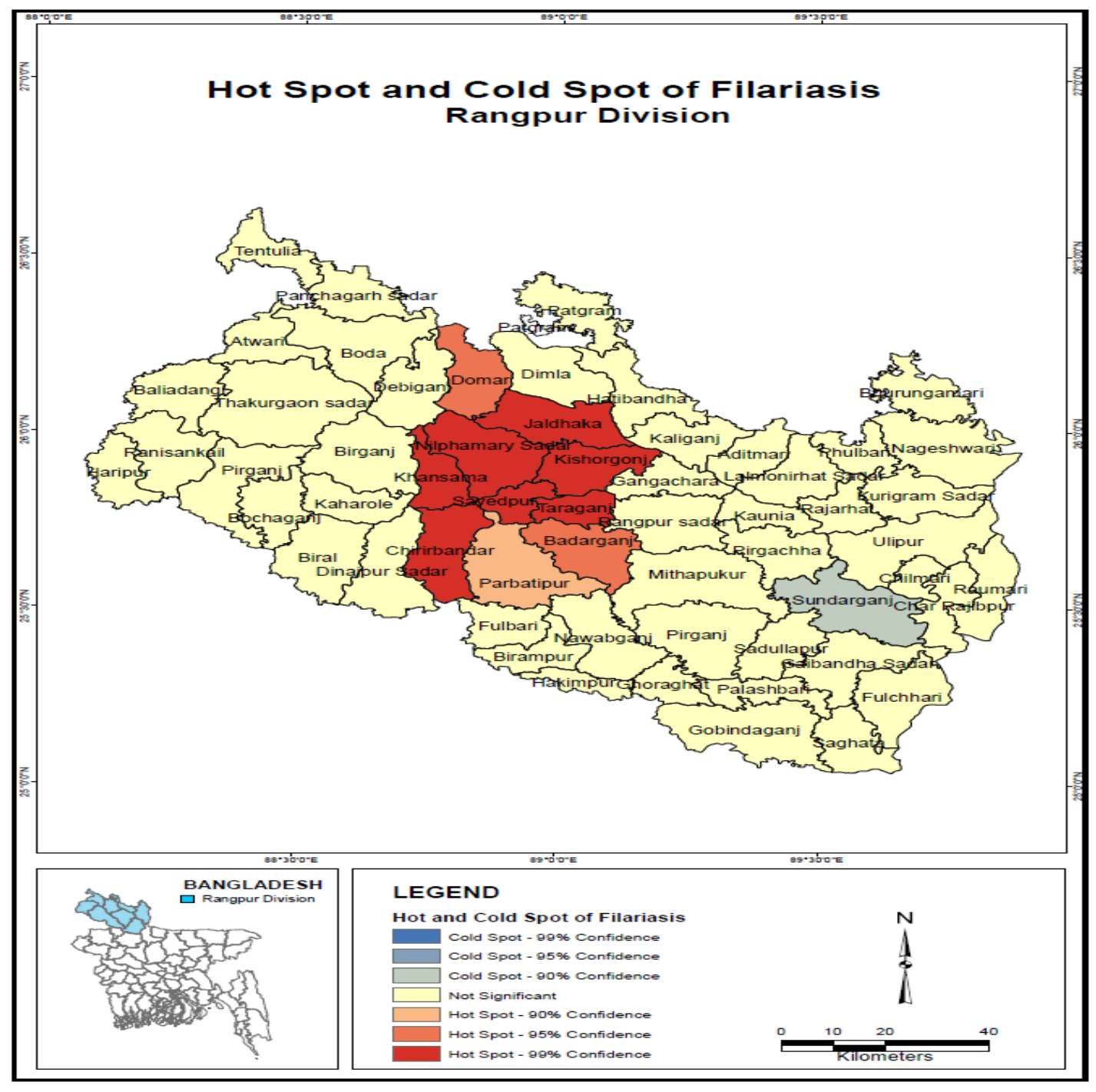

Map1: Hot Spot and Cold Spot of Filariasis

\subsection{Visualizing the Results}

There are many ways to create an interpolated surface that will effectively visualize the results of a hot spot analysis. The method that is used in this analysis is known as Inverse Distance Weighting (IDW), (Spatial Analyst), interpolates a raster surface from points using an inverse distance weighted technique. Surface interpolation tools create a continuous (or prediction) surface from sampled point values. The continuous surface representation of a raster dataset represents some measure, such as the 
Filariasis Morbidity, Environment and Socio-Economic Situation: A Hot Spot Analysis on Northern Region of Bangladesh

height, concentration, or magnitude (for example, elevation, acidity, or noise level). Surface interpolation tools make predictions from sample measurements for all locations in an output raster dataset, whether or not a measurement has been taken at the location. Therefore the analysis was run with the parameters mentioned in (Table 1).

Table1: Required Parameters for IDW

\begin{tabular}{|l|l|}
\hline Input Point Features & Filariasis Hot Spot \\
\hline Z value field & GiZScore \\
\hline Output Raster & Visualization Surface \\
\hline Output Cell Size & Default \\
\hline Power & Default \\
\hline Search Radius & Default \\
\hline Number of Points & Default \\
\hline Maximum distance & Default \\
\hline Input barrier polyline features & Default \\
\hline
\end{tabular}

Examination of only the upazilas identified as hot spots reveals the most intensely affected areas within the central parts of the region (Map 2). All of these upazilas are grouped together, but the hot spots are divided into three groupings based on confidence levels. There are four upazilas that are very strongly associated have a 99 percent confidence-level fit; this grouping includes the upazilas like Nilphamari Sadar, Jaldhaka, Kishorganj and Sayedpur. Their grouping is within the area encompassed by the second group. There are nine upazilas, in a much tighter spatial grouping, are more strongly associated (at the 95 percent confidence level) and the upazilas are Domar, Badarganj, Taraganj, Parbatipur, Chirirbandar, Khansama and some parts of Debiganj, Dimala, Jaldhaka and Kishorganj and twelve upazilas, at the 90 percent confidence level. Their position is at the outliers of the second group.

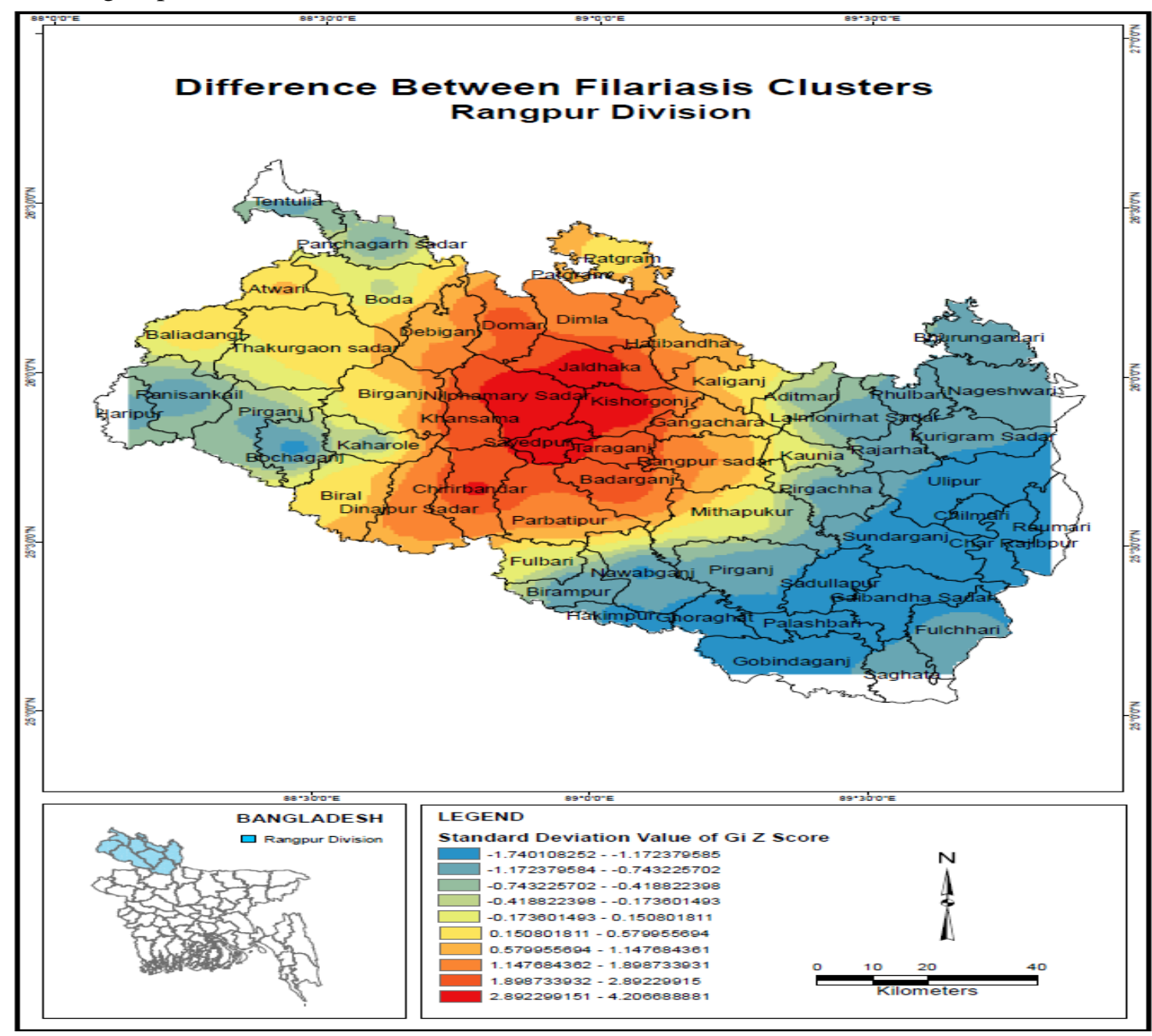

Map2: Difference between Filariasis Clusters 
Conversely, the cold spots can also be analyzed. The upazilas identified as cold spots are not grouped as tightly clustered as are the "Hot Spot" upazilas (Map 2). Most of these upazilas are in northern location, but more than a dozen cold spot are found in the southern location of the study area. The group of six upazilas such as, Thakurgaon Sadar, Baliadangi, Boda and most of the parts of Birganj, Kaharole, Birol related at a 90 percent confidence level (Map 2). There are twelve upazilas like Tetulia, Panchagarh Sadar, Pirganj, Haripur, Ranisankail, Lalmonirhat Sadar, Pirgacha, Bhurungamari, Aditmari, Fulbari and Kaunia with a 95 percent confidence level of association with the cold spots (Map 2). Rests of the upazilas are grouped together in southern part of the study area and reflect a confidence level of 99 percent association with the cold-spot characteristic. Therefore, it can be stated that the Filariasis clusters vary from one upazila to another. Hot Spot analysis can provide decision-makers with an understanding of the spatial patterns of Filariasis or any other disease and enabled them to make more informed decisions about how to address the disease occurrences issue and allocate resources in this respect.

\section{CONCLuSion}

The hot spot analysis brings forward the fact that Filariasis disease occurrence is clustered in the northern region of Bangladesh. Each upazilas has a number of patients who suffer from Filariasis. But the pattern of high incidences of Filariasis affected patients is clustered in some areas and it can also be found that the transmission of Filariasis is a natural phenomenon and therefore, it does not consider administrative boundaries, which are arbitrarily fixed. The spatial regression model developed with the help of GIS explores spatial relationship which depicts that the determinants of Filariasis of the study area. The models are statistically significant and best fitted. It seems that all the socio-economic and environmental variables have a significant impact on the Filariasis morbidity in the study area and the results lead to the rejection of the first null hypothesis suggesting that the identified factors significantly explain Filariasis morbidity in the study area.

\section{REFERENCES}

[1] Bangladesh Bureau of Statistics (2011a). Population and housing census, Dhaka: Ministry of Planning.

[2] Bangladesh Bureau of Statistics (2011b). Population and housing census, Socio-Economic and Demographic Report, National Series, Volume-4, Dhaka: Ministry of Planning.

[3] Bangladesh Bureau of Statistics (2011c). Population and housing census, Community Series: ZilaPanchagarh, Thakurgaon, Dinajpur, Nilphamari, Lalmonirhat, Kurigram, Rangpur, Gaibandha. Dhaka: Ministry of Planning.

[4] Directorate General of Health Services (2012). Health Bulletin, Dhaka: Ministry of Health and Family Welfare.

[5] Directorate General of Health Services (2014). Health Bulletin, Dhaka: Ministry of Health and Family Welfare.

[6] Durrheim, D. N., Wynd, S., Liese, B. and Gyapong, J. O. (2004). Lymphatic filariasis endemicity - an indicator of poverty? Tropical Medicine and International Health, volume 9 no 8 pp 843-845.

[7] ESRI (2014). Hot Spot Analysis (Getis-Ord Gi*), Retrieved from http://resources. arcgis. com/en/help/main/10.2/index.html\#//005p00000010000000, accessed on December 14, 2014.

[8] ESRI (2014). Understanding Cokriging, Retrieved from http://resources.arcgis.com/en/help/ main/10.2/index.html\#//003100000053000000, accessed on January 15, 2015.

[9] ESRI (2014). Ordinary Least Square, Retrieved from http://resources.arcgis.com/en/help/main/10.2/index. html\#//005p00000022000000, accessed on, December 14, 2014.

[10] ESRI (2014). Geographically Weighted Regression, Retrieved from http://resources.arcgis.com/en/help/ main/10.2/index.html\#l

[11] Geographically_Weighted_Regression_GWR/005p00000021000000/, accessed on December 16, 2014.

[12] ESRI (2014). Spatia Statistics. Retrieve from http://resources.arcgis.com/en/help/main/10.2/ index.html\#// 005p00000011000000, accessed on December 10, 2014.

[13] ESRI (2014). Understanding Cokriging. Retrieve from http://resources.arcgis. com/en/help/main/10.2/ index.html\#//003100000053000000, accessed on January 15, 2015.

[14] Fan, S. (2012). The spatial Temporal Prediction of Various Crime Types in Houston, TX Based on HotSpot Techniques. Unpublished Thesis. B.E. Central University.

[15] IACIB (2014). Filariasis. Retrieve from http://iacib.org/filariasis/, accessed on May 20, 2014.

[16] Kanda, K. (2004).The quality of life among lymphedema patients due to lymphatic filariasis in three rural towns in Haiti. Graduate Theses and Dissertations. http://scholarcommons. usf.edu/ etd/1105. 
Filariasis Morbidity, Environment and Socio-Economic Situation: A Hot Spot Analysis on Northern Region of Bangladesh

[17] Michael, E., Bundy, D.A., Greufell, B. T. (1996). Re-assessing the Global Prevalence and Distribution of Limphatic Filariasis. Parasitology, 112(pt.4), p.409:428.

[18] Ngwira, B.M.N., Tambala, P., Perez, A.M., Bowie, C. and Molyneux, D.H. (2007). The Distribution of Lymphatic Filariasis Infection in Malawi. Filaria Journal. 6:12, http://www.filariajournal com/content/2/ 1/2012, accessed on July 10, 2013.

a. Sasa, M. (1976). Human Filariasis, Baltimore: University Park Press.

[19] WHO (1995). Lymphatic filariasis: the disease and its control. World Health organization Geneva: Technical Report Series, 821:1-71.

[20] WHO (1995). The World Health Report 1995: Bridging the gaps. Geneva: World Health Organization.

Citation: Rashed Karim, Sheikh Md. Monzurul Huq, Shams Shaila Islam. Filariasis Morbidity, Environment and Socio-Economic Situation: A Hot Spot Analysis on Northern Region of Bangladesh. International Journal of Research in Geography. vol 4, no. 3, 2018, pp. 36-43. doi:http://dx.doi.org/10.20431/2454-8685.0403003.

Copyright: (C) 2018 Authors. This is an open-access article distributed under the terms of the Creative Commons Attribution License, which permits unrestricted use, distribution, and reproduction in any medium, provided the original author and source are credited. 